make a referral to the FAS clinic?"

I think back about that kid a couple of weeks ago — the same story arc. A loaded history including parental mental illness and addiction, early abuse and neglect, changing caregivers in the early years, interrupted relationships all these factors adversely affecting this developing child ... and then reducing it all to this single exposure, a single diagnosis. FAS.

So what's next, Johnny? You'll get a four-digit FAS diagnostic code. You'll get special school coding. Maybe you'll get special mentorship or access to special programs. We will lower our expectations of you. It's not your fault. You apparently can't tell right from wrong. I have been told our evidence-based therapies for your behaviours don't work for kids with FAS, so we won't try them.

Remember, your new label is not supposed to incriminate your mom. Maybe your mom didn't drink during pregnancy. It was not a "reliable, confirmed drinking history." Maybe she only did drugs. Maybe you were just exposed to a lot of other shit. Maybe you inherited some bad genes. Johnny, I'm sorry, but I am not that smart. I don't know what got you into this predicament. I'm not sure you are going to benefit from your new label. I'm not sure what's in store for you. Maybe I am doing you more harm than good. We'll see what the FAS clinic comes up with. I hate this screening and then $\mathrm{f} * * *$ ing random punting. Our next case is up ...

\section{John D. McLennan MD}

Child Psychiatry Consultant, Cumming School of Medicine, University of Calgary, Calgary, Alta.

CMAJ 2015. DOI:10.1503/cmaj.150041

Editor's note: Johnny is a composite of many patients who may or may not have fetal alcohol syndrome.

\title{
A false dichotomy
}

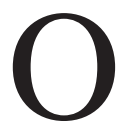
$\mathrm{n}$ the first day of medical school, I was told "medicine is an art and a science." Since then, that phrase, or some variation of it, has been repeated to me at least weekly. My teachers have portrayed art and science as a dichotomy, equating science with factual, evidencebased truth while invoking the art of medicine to explain how epidemiologic factors do not apply to particular patients and how physicians must deal with uncertainty. However, this is a false dichotomy: art and science have much more in common than is suggested by the binary phrase "the art and science of medicine."

Recently, a number of medical educators have identified problems with how the arts, social sciences and humanities are addressed in medical school curricula. There is thus growing interest in developing more rigorous and nuanced approaches to the art of medicine. ${ }^{1}$ In contrast, the way in which science is taught in medical school is not generally seen as problematic. But the construction of science as facts and evidence is an oversimplification that must also be considered by medical educators. The equating of science solely with statements of truth and guidelines eliminates the complexity and beauty that draw many scientists to science - and that drew me to chemistry.

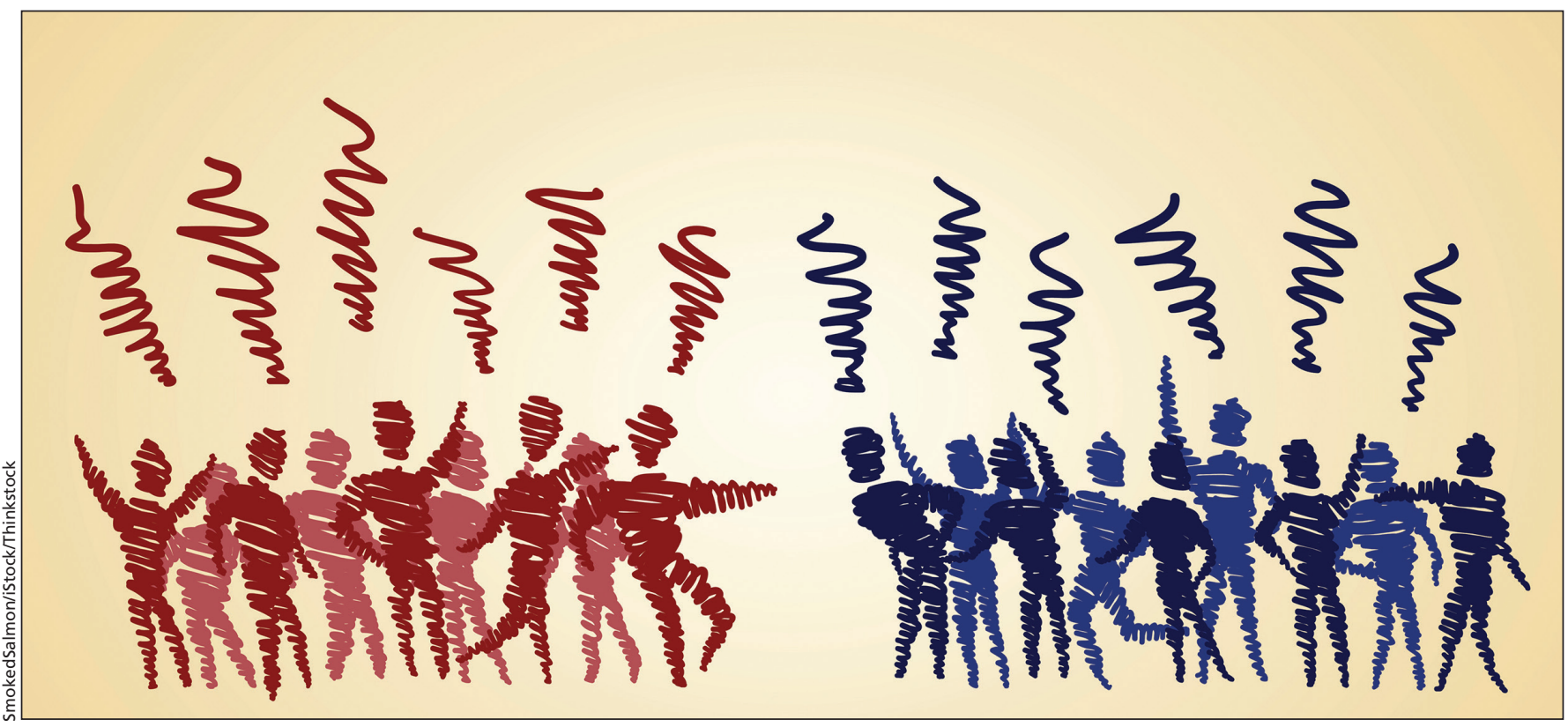


Before medical school, I thought of myself as a scientist. As part of my undergraduate degree in chemistry, I completed my senior thesis in Nobel Laureate E.J. Corey's laboratory at Harvard University, where I explored the mechanism of a specific sulfide oxidation reaction that produces only one of two possible enantiomeric products. ${ }^{2}$ Chemistry research requires the mastery of a large body of background knowledge, but the mastery of that knowledge, although necessary, is not sufficient. Chemists must also be creative when presented with a new problem. Research laboratories are filled with uncertainty: data must be interpreted, even if they appear to be contradictory. There is no strict set of rules and guidelines that one follows to be "scientific." In my experience, science requires innovation and creative thinking.
Bourdieu further explains that the formal language of scientific writing hides the passionate engagement with ideas and methods that is required for innovative experimentation. Quoting Medawar, he notes that in the scientific literature

[T] he most creative aspects of the research disappear, giving the impression that imagination, passion, art have played no part in them and that the innovation results not from the passionate activity of the deeply committed hands and brains but from passive submission to the sterile precepts of the so-called 'Scientific Method.'

As scientists strive to appear impersonal and objective in published materials, the creativity, imagination and innovation that were necessary to obtain those results are ignored and hidden.

Social scientists, then, describe science as involving uncertainty, chaos

\section{The construction of science as facts and evidence is an oversimplification.}

My experience is supported by the research of many social scientists who study natural scientists. They describe science as being much more than truth statements; rather, they explain that scientific research is filled with complexity and ambiguity. For example, Latour and Woolgar describe the process of interpreting the vast amount of data generated in a research laboratory as contending with disorder and confusing results. Patterns do not simply emerge out of the data to fit immediately into a theoretical model. Rather, data analysis often involves dealing with chaos and "negotiation with utter confusion."3

Kuhn likewise comments on the inherent disorder that exists within science, describing it as "a rather ramshackle structure with little coherence among its various parts." ${ }^{\prime 4}$ According to Kuhn, scientists are constantly solving puzzles, and it is rare that a particular field of science will resolve all of its problems. ${ }^{4}$ and creativity. The decision of medical educators to limit science's thoughtprovoking nature by simplistically constructing it as a field of certainty and truth does little for science, and even less for medicine. Scientific research involves substantial uncertainty, creativity and nuance; the teaching of the science of medicine should therefore incorporate these essential aspects of science, rather than position them as the art of medicine.

As essential as creativity is in scifundamental in art. In addition to being trained as a chemist, I am also a cellist, so I understand that music is extremely structured. Like music, other arts such as painting, writing, sculpture and dance involve rigour and years of training. It would be impossible to determine whether the demand for rigour was greater in the orchestra or the chemistry laboratory; it would be equally impossible to decide which required more creativity. ence, so too are rigour and technique
The dualism of art versus science in medical school lectures is at odds with my experience as a chemist and cellist. As a scientist and musician, I appreciate the vast knowledge and technical skill that must be mastered in both the arts and the sciences. I am also aware that beauty, creativity and nuance are the exclusive domain of neither. As a medical student, it seems to me that medicine requires similar mastery of knowledge, technical skills and creativity. Instead, as medical students, we are taught to seek facts and truth statements that must be memorized for the next exam. Areas of uncertainty are relegated to the art of medicine, which is portrayed as a separate, less rigorous component of the curriculum. This separation creates a false sense of certainty about the science of medicine and leaves little room for creativity. Rather than having medical students understand the practice of medicine as a peculiar combination of factual science and fluffy art, medical educators must find ways to move beyond that unnecessary dichotomy and teach a more nuanced understanding of medicine.

\section{Clare Whitehead AB}

Faculty of Medicine, University of Ottawa, Ottawa, Ont.

\section{Ayelet Kuper MD DPhil}

Assistant professor, Department of Medicine, Sunnybrook Health Sciences Centre and Wilson Centre for Research in Education, University of Toronto, Toronto, Ont.

Editor's note: The first-person narrator in this essay is Clare Whitehead.

\section{References}

1. Jones AH. Why teach literature and medicine? Answers from three decades. J Med Humanit 2013;34:415-28

2. Newhouse TR, Li X, Blewett M, et al. A tetradentate ligand for the enantioselective Ti(IV)promoted oxidation of sufides to sulfoxides: origin of enantioselectivity. J Am Chem Soc 2012; 134:17354-7.

3. Latour B, Woolgar S. Laboratory life: the construction of scientific facts. New Jersey: Princeton University Press; 1986

4. Kuhn T. Structure of scientific revolutions. Chicago: University of Chicago Press; 1996.

5. Bourdieu P. Science of science and reflexivity. Cambridge: Polity Press; 2004.

CMAJ 2015. DOI:10.1503/cmaj.140839 